\title{
ATIVISMO JUDICIAL E A SEPARAÇÃO DOS PODERES NO SÉCULO XXI: EXORBITAÇÃO DA FUNÇÃO ATÍPICA DO PODER JUDICIÁRIO
}

Luís Henrique Ramos Alves, Shirley Oliveira Lima Nomura.

Universidade do Oeste Paulista - UNOESTE, Curso de Direito, Presidente Prudente, SP. E-mail: luishenrique981@hotmail.com

\section{RESUMO}

A separação dos poderes é um princípio geral do direito Constitucional Brasileiro prescrito no artigo 20 da Constituição Federal seguindo o modelo idealizado por Montesquieu, Executivo, Legislativo e Judiciário, cada um dos poderes possui suas respectivas características e possui também suas funções típicas e atípicas. No sistema de separação dos poderes há uma Teoria chamada de Sistema de Freios e Contrapesos, onde controla a divisão dos poderes e garante que cada um atue dentro de sua respectiva esfera de competência.

Com o passar do tempo dentro do cenário Brasileiro vem surgindo o chamado Ativismo Judicial, um fenômeno que nasce quando o poder judiciário passa a intervir de maneira proativa na esfera de competência dos outros poderes.

Com isso o presente artigo busca mostrar o ativismo judicial, com foco na exorbitação da função atípica do poder judiciário e como que esse ativismo judicial é desencadeado dentro do sistema de separação dos poderes.

Palavras - chaves: Ativismo, Separação, Poderes, Exorbitação, Função.

\section{JUDICIAL ACTIVISM AND THE SEPARATION OF POWERS IN THE 21 ST CENTURY: EXORBITANCE OF THE ATYPICAL FUNCTION OF THE JUDUCIARY}

\begin{abstract}
The separation of powers is a general principle of Brazilian Constitutional law prescribed in article 2 of the Federal Constitution following the model idealized by Montesquieu, Executive, Legislative and Judiciary, each of the powers has its respective characteristics and also has its typical and atypical functions. In the system of separation of powers there is a theory called System of Brakes and Counterweights, where it controls the division of powers and ensures that each one acts within its respective sphere of competence.

With the passage of time within the Brazilian scenario has been emerging the so-called Judicial Activism, a phenomenon that arises when the judiciary proceeds to intervene proactively in the sphere of competence of other powers.

With this, the present article seeks to show judicial activism, focusing on the exorbitance of the atypical function of the judiciary and how this judicial activism is triggered within the system of separation of powers.
\end{abstract}

Keywords: Activism, Separation, Powers, Exorbitant, Function. 


\section{METODOLOGIA}

O Presente trabalho foi desenvolvido através de um levantamento bibliográfico sobre o ativismo judicial e a separação dos poderes, buscando analisar cada poder e suas funções e fazer um paralelo com o fenômeno do ativismo judicial. Com isso foi utilizado livros, artigos eletrônicos e bibliotecas virtuais. Para o presente artigo foi se utilizado o método hipotético dedutivo, a partir da análise da legislação vigente e doutrina, buscando trabalhar com hipóteses que poderão ocorrer, não há uma total veracidade mas sim uma possibilidade.

\section{INTRODUÇÃO}

A separação dos poderes é um princípio geral do Direito Constitucional Brasileiro disposto no art. 2o da Constituição Federal que diz que "são poderes da União, independentes e harmônicos entre si, o Legislativo, o Executivo e o Judiciário", esse princípio precisa ser entendido para que se reconheça o Estado Democrático de Direito. Com isso, é essencial que esse princípio seja observado, como forma de atender ao Constitucionalismo e manter o organismo estatal. 0 modelo de estrutura de separação dos poderes que se aplica no Brasil fora o idealizado por Montesquieu, compreendendo a separação das funções estatais em três esferas, correspondendo aos poderes já citados. Além disso a Separação dos Poderes é uma Cláusula Pétrea, não podendo ter a sua aplicabilidade afastada, essa garantia se encontra no art. 60, §4ㅇ, III, "Não será objeto de deliberação a proposta de emenda tendente a abolir: a separação dos Poderes". De acordo com Dallari:

O Sistema de separação dos poderes, consagrado nas Constituições de quase todo o mundo, foi associado à ideia de Estado Democrático e deu origem a uma engenhosa construção doutrinária, conhecida como sistema de freios e contrapesos. DALLARI, 2012, p. 218.

O Brasil vem passando por um Ativismo Judicial muito grande, o Poder Judiciário vem interferindo de maneira regular e significativa nas opções políticas dos demais poderes, exorbitando sua função atípica e desrespeitando a Separação de Poderes.

Com isso o objetivo do presente artigo é trazer um levantamento sobre o contexto histórico da separação dos poderes, suas funções e características, a aplicação do sistema de freios e contrapesos e análise da exorbitação da função atípica do poder judiciário em relação aos outros poderes, fazendo com que venha nascer o ativismo judicial.

\section{DISCUSSÃO}

\section{OS PODERES: FUNÇÕES E CARACTERÍSTICAS}

Atualmente contamos com 3 poderes na República Federativa do Brasil, Executivo, Legislativo e Judiciário, ambos consagrados na Constituição de 1988 "São Poderes da União, independentes e harmônicos entre si, o Legislativo, o Executivo e o Judiciário". De acordo com Alexandre de Moraes:

A Constituição Federal, visando, principalmente, evitar o arbítrio e o desrespeito aos direitos fundamentais do homem, previu a existência dos Poderes do Estado e da instituição do Ministério Público, independentes e harmônicos entre si, repartindo entre eles as funções estatais e prevendo prerrogativas e imunidades para que bem pudessem exercê-las, bem como criando mecanismos de controles recíprocos, sempre como garantia da perpetuidade do Estado democrático de Direito. Moraes, 2016, p. 432.

Levando em consideração que a Constituição Federal diz que os poderes são independentes e harmônicos, se faz necessário fazer uma análise de cada poder.

Poder Executivo é o poder responsável pela administração dos interesses públicos e governar o povo, o artigo 76 da Constituição diz que "O Poder Executivo é exercido pelo Presidente da República, auxiliado pelos Ministros de Estado." O chefe do poder executivo atua 
como chefe de governo e chefe de Estado, como chefe de Estado representa o país na órbita internacional, e como chefe de governo exerce a liderança da política nacional e pela direção da máquina administrativa. O Presidente, que exerce o cargo de chefe do poder executivo é eleito pelo sistema eleitoral majoritário, onde é considerado eleito o candidato que obtiver o maior número de votos, além disso é eleito pelo sufrágio universal e pelo voto direto e secreto, art. 14 Constituição. O Chefe do Poder Executivo possui funções que são elencadas pela própria Constituição, suas atribuições estão descritas no art. 84 da CF. Entretanto temos as suas funções típicas e atípicas, como função típica o poder executivo possui a prerrogativa de administrar a coisa pública, de onde deriva o nome república Res Publica, e como função atípica possui a prerrogativa de legislar através das Medidas Provisórias (art. 62 CF) e julga os contenciosos administrativos.

Poder Legislativo é o poder responsável por legislar, criar as leis e normas e fiscalizar. 0 Poder Legislativo Federal é Bicameral, o art. 44 da Constituição traz que "O Poder Legislativo é exercido pelo Congresso Nacional, que se compõe da Câmara dos Deputados e do Senado Federal". A Câmara dos Deputados compõe-se de representantes do povo, eleitos pelo sistema proporcional em cada Estado, os deputados possuem mandato de 4 anos; suas competências estão elencadas no art. 51 da Constituição. O Senado Federal compõe-se de representantes dos Estados e do Distrito Federal que são eleitos pelo chamado sistema majoritário, com mandato de 8 anos, suas matérias de competência estão descritas no art. 52 da Constituição. O Poder Legislativo assim como o executivo possui duas Funções Típicas e Atípicas, como função típica o poder legislativo possui a competência para criar, aprovar e rejeitar leis dentro do ordenamento jurídico brasileiro, como função atípica estão no âmbito de administração de seus setores e de julgar determinados crimes como é o caso do Crime de Responsabilidade art. 52, I, CF.

Poder Judiciário é um dos três poderes e consagrado como um poder autônomo e independente de suma importância, possui como função interpretar as normas e administrar a justiça, função não se limita somente a isso, pois seu mister é ser o verdadeiro guardião da Constituição, buscando preservar os preceitos e os princípios constitucionais. Zaffaroni diz p. 87 que "a chave do poder judiciário se acha no conceito de independência". De acordo com Alexandre de Moraes:

Não se consegue conceituar um verdadeiro Estado democrático de direito sem a existência de um Poder Judiciário autônomo e independente para que exerça sua função de guardião das leis. É preciso um órgão independente e imparcial para velar pela observância da Constituição e garantidor da ordem na estrutura governamental, mantendo nos seus papéis tanto o Poder Federal como as autoridades dos Estados Federados, além de consagrar a regra de que a Constituição limita os poderes dos órgãos da soberania. Moraes, 2016, p. 530.

A Constituição Federal em seu artigo 92, elenca os órgãos do Poder Judiciário: o Supremo Tribunal Federal, o Conselho Nacional de Justiça, o Superior Tribunal de Justiça, os Tribunais Regionais Federais e Juízes Federais, os Tribunais e Juízes do Trabalho, os Tribunais e Juízes Eleitorais, os Tribunais e Juízes Militares e os Tribunais e Juízes dos Estados e do Distrito Federal e Territórios.

O Poder Judiciário possui como função típica a função jurisdicional, julgar aplicando a lei a um caso concreto, que lhe é colocado, que resulta de um conflito de interesses. Possui como função atípica, funções de natureza administrativa e legislativa, administrativa o judiciário tem autonomia para por exemplo, conceder férias aos seus membros, legislativa a edição de normas regimentais, a edição de súmulas, súmulas vinculantes e regimentos internos. 


\title{
TEORIA DOS SITEMAS DE FREIOS E CONTRAPESOS “CHECK AND BALANCES”
}

A Constituição Federal de 1988, assegura em nível de cláusula pétrea a separação dos poderes (art. 2ㅇ CF), visando evitar que um dos poderes usurpe sua função e entre na esfera do outro poder, com isso consolidou-se a chamada separação dos poderes, transformando-os em independentes e harmônicos entre si, que é chamado de "Sistemas de Freios e Contrapesos".

O Poder em si é soberano, o que se divide na realidade são as funções, Legislativa, Judiciária e Executiva. Este sistema criou mecanismos para haver um controle recíproco, sempre com o objetivo de garantir a perpetuidade do Estado Democrático de Direito. De acordo com DALLARI:

\begin{abstract}
O sistema de separação dos poderes, consagrado nas Constituições de quase todo o mundo, foi associado à ideia de Estado Democrático e deu origem a uma engenhosa construção doutrinária, conhecida como sistema de freios e contrapesos. Segundo esta teoria os atos que o Estado pratica podem ser de duas espécies: ou são atos gerais ou são especiais. Os atos gerais, que só podem ser praticados pelo poder legislativo, consistem na emissão de regras gerais e abstratas, não se sabendo, no momento de serem emitidas, a quem elas irão atingir. Dessa forma, o poder legislativo, que só pratica atos gerais, não atua concretamente na vida social, não tendo meios para cometer abusos de poder nem beneficiar ou prejudicar uma pessoa ou um grupo em particular. Só depois de emitida a norma geral é que se abre a possibilidade de atuação do poder executivo, por meio de atos especiais. $O$ executivo dispõe de meios concretos para agir, mas está igualmente impossibilitado de atuar discricionariamente, porque todos os seus atos estão limitados pelos atos gerais praticados pelo legislativo. E se houver exorbitância de qualquer dos poderes surge a ação fiscalizadora do poder judiciário, obrigando cada um a permanecer nos limites de sua respectiva esfera de competência. DALLARI, 2012, p. 218.
\end{abstract}

Importante lembrar que o sistema de freios e contrapesos serve para garantir que haja a total eficácia da separação dos poderes, criando possibilidades de cada poder, no exercício da sua competência atribuída pela Constituição, controlar outro poder e também se submeter ser controlado por outro poder, sem haja bloqueio ao funcionamento da sua atuação. Aplicar o sistema de freios e contrapesos, significa buscar o combate aos abusos praticados por outros poderes para manter o equilíbrio dentro do Estado Democrático de Direito.

\section{ATIVISMO JUDICIAL}

O Ativismo judicial é considerado como um fenômeno jurídico, se dá o ativismo judicial com a interferência do poder judiciário nas opções políticas dos demais poderes; entende-se ainda como um papel inovador dos tribunais em trazer novas contribuições para o Direito. Muitos acreditam que o Ativismo Judicial, na realidade é uma escolha do próprio magistrado que busca através da sua interpretação jurídica, concretizar um valor normativo constitucional, garantindo direitos as partes, e buscando soluções aos litígios e às necessidades derivadas da lentidão ou até mesmo ante a omissão legislativa, ou até mesmo do próprio executivo. Elival da Silva Ramos define ativismo judicial como:

Exercício da função jurisdicional para além dos limites impostos pelo próprio ordenamento que incumbe, institucionalmente, ao Poder Judiciário fazer atuar, resolvendo litígios de feições subjetivas (conflitos de interesse) e controvérsias jurídicas de natureza objetiva (conflitos normativos). Há como visto, uma sinalização claramente negativa no tocante às práticas ativistas, por importarem na desnaturação da atividade típica do Poder Judiciário, em detrimento dos demais Poderes. Não se pode deixar de registrar mais uma vez, o qual tanto pode ter o produto da legiferação irregularmente invalidado por decisão ativista (em sede de controle de constitucionalidade), quanto o seu espaço de conformação normativa invadido por decisões excessivamente criativas. RAMOS, 2010, p. 129. 


\section{ATIVISMO JUDICIAL E A SEPARAÇÃO DOS PODERES NO SÉC XXI: EXORBITAÇÃO DA FUNÇÃO ATÍPICA DO PODER JUDICIÁRIO}

Atualmente uma das principais críticas feitas ao fenômeno do ativismo judicial é a maneira em que o Poder Judiciário interfere nos outros poderes, o poder judiciário atualmente tem deixado de lado a função de apenas julgar de acordo com as leis passando a julgar e a legislar. Modernamente os juízes, Tribunais e principalmente os Tribunais Constitucionais, exercem atos contrários aos legalmente instituídos pelos poderes Legislativo e Executivo, sendo que não possuem legitimidade democrática para tal atitude, isso é claramente visto pois o STF (Supremo Tribunal Federal) vem fazendo análise política e não jurídica, e diante disso começa os questionamentos a quem cabe fazer ou criar normas o poder legislativo ou judiciário?

Dentro do cenário político Brasileiro está cada dia mais difícil definir as competências de cada poder e fazer uma separação exata das funções pois um faz a função do outro por inércia deste e vice-versa, é possível de se observar isso quando o poder Legislativo deixa de atender as demandas sociais de forma efetiva e passa a se preocupar com elegibilidade e não com os anseios sociais, às vezes deixam de legislar para poderem garantir votos na próxima eleição fazendo com que o poder judiciário exerça de maneira exorbitante a sua função atípica pois passa na realidade a legislar em vez de julgar, fazendo com que a separação dos poderes que é garantida no artigo 20 da Constituição Brasileira fique relativizada. O judiciário tem que julgar e não criar normas, o legislativo que tem legitimidade para isso, pois foram escolhidos pelo povo para fazer a vontade do povo, e devem legislar para garantir a eficácia da separação dos poderes. Além disso observando-se pela Teoria do Sistema de Freios e Contrapesos o Judiciário deve ficar dentro da sua esfera de competência e exercer a sua função atípica quando necessária para não banalizar a separação dos poderes.

\section{CONCLUSÃO}

Com isso é possível de se concluir que o Ativismo Judicial está cada dia mais presente dentro do Cenário Brasileiro, fazendo com o Poder Judiciário interfira de maneira significativa dentro dos outros poderes, resultando em uma relativização da separação dos poderes e trazendo um risco para o cumprimento da Constituição Brasileira. Além disso devemos que o poder judiciário interferindo nos outros poderes há o nascimento do ativismo judicial, mas muitas vezes essa interferência nas por questões políticas e até mesmo pela inércia do poder legislativo e criar normas, por não se preocupar com os anseios sociais e sim com questões de elegibilidade.

\section{REFERÊNCIAS.}

DALLARI, Dalmo de Abreu. Elementos de Teoria Geral do Estado. 31.ed. - São Paulo: Saraiva, 2012.

LENZA, Pedro. Direito Constitucional Esquematizado. 20.ed. rev., atual. e ampl. - São Paulo: Saraiva, 2016.

MORAES, Alexandre de. Direito Constitucional. 32.ed. rev. e atual. - São Paulo: Atlas, 2016.

RAMOS, Elival da Silva. Ativismo judicial: parâmetros dogmáticos. São Paulo: Saraiva, 2010.

ZAFFARONI, Eugenio Raúl. Poder Judiciário, Trad. de Juarez Tavares. São Paulo: Revista dos Tribunais, 1995. p.87.

BRASIL. Constituição da República Federativa do Brasil de 1988. Disponível em: <http://www.planalto.gov.br/ccivil_03/constituicao/constituicaocompilado.htm>. Acesso em: $10 / 06 / 2018$. 
BRASIL, Direitos. Três poderes do Estado: qual a função de cada um?. Disponível em: $<$ https://direitosbrasil.com/tres-poderes-estado-qual-funcao-de-cada-um/>. Acesso em: 19/05/2018.

BEVENUTO, Daniel. O Poder Judiciário na organização do Estado democrático de Direito. Disponível em: <https://jus.com.br/artigos/25950/o-poder-judiciario-na-organizacao-do-estadodemocratico-de-direito>. Acesso em: 19/05/2018.

CYSNE, Diogo.Poder Judiciário. Disponível em: <https://www.infoescola.com/direito/poderjudiciario/>. Acesso em: 10/06/2018.

GUIMARÃES, Rodrigo Leventini. A harmonia dos três poderes e a composição do Supremo Tribunal Federal através do Sistema de Freios. Disponível em: $<$ http://www.migalhas.com.br/dePeso/16,Ml8267,31047-

Atharmonia+dos+tres+poderes+e+a+composicao+do+Supremo+Tribunal>. Acesso em: 10/06/2018.

MATOS, Francisco de Castro. Separação dos Poderes: sistema de Freios e Contrapesos. Disponível em: $\quad$ <https://jus.com.br/artigos/52803/separacao-dos-poderes-sistemas-de-freios-econtrapesos>. Acesso em: 10/06/2018.

GRANJA, Cícero Alexandre. O Ativismo Judicial no Brasil como mecanismo para concretizar os direitos fundamentais. Disponível em: <http://www.ambitojuridico.com.br/site/?n_link=revista_artigos_leitura\&artigo_id=14052>. Acesso em: 23/06/2018.

MEDEIROS, Amanda. Judicialização ou Ativismo Judicial? Entenda a diferença. Disponível em: <http://www.politize.com.br/judicializacao-e-ativismo-judicial/>. Acesso em: 23/06/2018. 